\title{
Verein Rheinisch-Westfälischer Augenärzte
}

Sitzung vom 5. Mai 1935 in Düsseldorf

Wegner (Freiburg i. Br.) (a. G.): Augenveränderungen bei Hypertonie und Verwandtes.

(Fortbildungsvortrag.)

Wüllenweber (Köln) (a. G.): Zusammenhang von Netzhautblutungen und

Allgemeinerkrankungen. (Fortbildungsvortrag.)

de Crinis (Köln) (a. G.): Anatomic, Physiologic und Pathologie dér Sehrinde.

(Fortbildungsvortrag.)

Vogelsang (Bonn): Pachymeningitis haemorrhagica interna mit Stauungspapille.

49jähriger Kranker. Beiderseits Stauungspapille von 2-3 Di. Links Konvergenzstellung mit geringem Höherstand. Rechts Überfunktion des Rect. inf. SR. 0,8; L. 0,4. Aphasie.

Klopfschmerz der linken Schläfen-gegend. Fazialisschwäche des rechten Mundast.

Reflexdifferenzen.

Operation (Chirurg. Klin.). Lappenschnitt über dem linken Stirn-hirn. Vorwölbung der Dura bläulich durchschimmernd. Nach Er-öffnung Bluthöhle, die die linke Hemisphäre bis hinter die Zentralwin-dungen bedeckt, unter der Dura von rötlicher, über der Pia von gelb-lich-fibröser

Membran ausgekleidet.

Diagnose: Subdurales Hämatom über dem linken Stirn- und Schlä-fenhirn.

Pathologischer Befund wie bei rezidivierender Pachymeningitis interna haemorrhagica.

Ätiologie: eventuell Fall, auf den Hinterkopf.

Bartels (Dortmund): Tumoren der Hypophysengegend.

Bericht über 16 zum Teil verkannte, zum Teil in der Sprechstunde entdeckte Fälle. Trotz großer Geschwülste können Jahrzehnte Seh-störungen fehlen, manchmal liegt nur Neuritis retrobulbaris vor. Andere haben schwere Sehstörungen bis zur ein- oder doppelseitigen Erblindung. Außer den sonstigen Augenkomplikationen (Augenmuskelstörungen, Glaukom, Stauungspapille u. a.) muß der Augenarzt auch die Allgemein-störungen kennen.

Aussprache.

Vogelsang (Bonn) bei alien Fallen von Zentralskotom, bes. doppel-seitigem und temporaler Abblassung der Papille ist an Erkrankungen der Chiasmagegend zu denken.

Custodis (Düsseldorf): P > eiträge zur Ophthalmoneu Cologie insbesondere zu der Diagnose der

Hirntumoren.

C. bespricht an der Hand einschlägiger Fälle die ophthalmologischen und röntgenologischen Veränderungen bei den aus dem Epipharynx nach dem Schädeldach zu wachsende Tumoren unter besonderer Berücksichti-

Verein Rheinisch Westfälischer Augenärzte. 61

gung der Differential-Diagnose zu den Geschwülsten, die von der mitt-leren Schädelgrube zum Epipharynx wachsen. Auf Grund mehrfacher gegenteiliger Erfahrungen halt er die stärkere Prominenz der Stauungs-papille einer Seite nicht für ein verwertbares seitendiagnostisches Symptom, während durch Röntgenaufnahmen die Seitendiagnose häufig richtig gestellt werden kann. 
Poos (Münster i. W.): Neue Untersuchungen am Auge mit der Gruppe der Sympathikusreizmittel.

(Erscheint in den Kl. M. f. A.)

Jaensch (Essen): Verfettung der Gefäßhaut.

Krankhaftes Fettvorkommen ist häui'g im Strahlenkörper und seinen Fortsätzen nachzuweisen, ähnlich der physiologischen Altersverfettung, seltener in Regenbogenhaut und Aderhaut. Sie gliedert sich in die der Wände von Arterien und Arteriolen, in intra- und extrazellulares Fettvorkommen im Stroma, in Verfettung der Chromatophoren, Epithelien und Muskelzellen. Die Verfettung entsteht durch Speicherung aus dem Blut-strom oder durch Zelltod und Nekrose. von Szily (Münster i. W.): Weitere Beiträge zur Kenntnis der follikel-Mldenden Erreger. Auf Grund der günstigen Erfahrungen mit Hühnern als Objekt für Übertragungsversuche mit menschlicher sympathischer Ophthalmie wurden ähnliche Versuche mit Trachommaterial durchgeführt, und zwar durch Injektion von o, i ccm stark verdünnter Gewebsaufschwemmung von menschlichem Trachomfollikel in den Glaskörperraum. Zunächst fand sich eine auffallende Vermehrung der Lymphfollikel in der Bindehaut von einem dichten Wall entzündlicher Infiltration aus Lymphozyten urn-geben. Ferner besonders große Follikel in der Umgebung und innerhalb des bindegewebigen Gerüstes der Tränendrüse. Die in den Glaskörperraum injizierte Masse sieht man in ihm als unregelmäßigen weißlichen Klumpen schweben. Innerhalb und außerhalb von diesem, sogar weit abliegend, entwickeln sich zumTeil aus neuen Keimzentren echte Follikel. Die Bildung der Keimzentren ist charakteristisch für diese Übertragungsversuche. 